\title{
Effect of Extra-Framework Cations on Negative Linear Compressibility and High-Pressure Phase Transitions: A Study of $\mathrm{KCd}\left[\mathrm{Ag}(\mathrm{CN})_{2}\right]_{3}$
}

Andrew B. Cairns,* Jadna Catafesta, Patrick Hermet, Jérôme Rouquette, Claire Levelut, David Maurin, Arie van der Lee, Vladimir Dmitriev, Jean-Louis Bantignies, Andrew L. Goodwin, and Julien Haines

Cite This: J. Phys. Chem. C 2020, 124, 6896-6906

Read Online

ACCESS | LW Metrics \& More | 国 Article Recommendations

Supporting Information

ABSTRACT: The negative thermal expansion material potassium cadmium dicyanoargentate, $\mathrm{KCd}\left[\mathrm{Ag}(\mathrm{CN})_{2}\right]_{3}$, is studied at high pressure using a combination of X-ray single-crystal diffraction, X-ray powder diffraction, infrared and Raman spectroscopy, and density functional theory calculations. In common with the isostructural manganese analogue, $\mathrm{KMn}\left[\mathrm{Ag}(\mathrm{CN})_{2}\right]_{3}$, this material is shown to exhibit very strong negative linear compressibility (NLC) in the crystallographic $c$ direction due to structure hinging. We find increased structural flexibility results in enhanced NLC and NTE properties, but this also leads to two pressure-induced phase transitions-to very large unit cells involving octahedral tilting and shearing of the structure-below $2 \mathrm{GPa}$. The presence of potassium cations has an important effect on the mechanical and

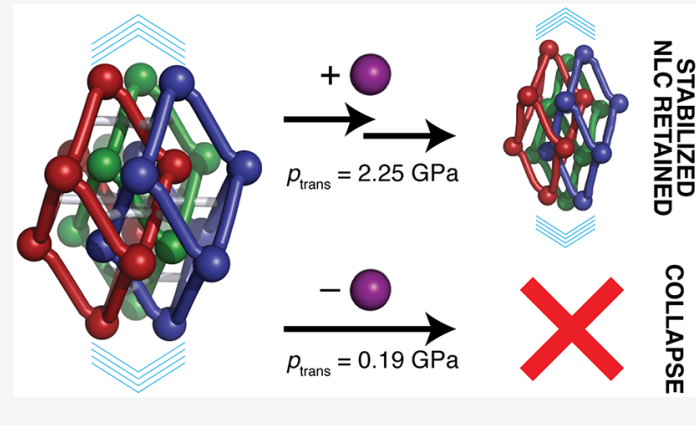
thermodynamic properties of this family, while the chemical versatility demonstrated here is of considerable interest to tune unusual mechanical properties for application.

\section{INTRODUCTION}

Materials where external stimuli induces an anomalous response, such as expansion upon cooling (negative thermal expansion, $\mathrm{NTE}^{1-3}$ ) or on application of hydrostatic pressure (negative linear compressibility, $\mathrm{NLC}^{4,5}$ ), have recently received considerable attention. These materials that "break the rules" - as a result of specific, and therefore rare, elastic anomalies $^{6-8}$ - are curious from a fundamental point of view but might also be revolutionary for a range of technologies including interferometric pressure sensors, pressure-controlled or pressure-sensitive electronic devices, and smart actuation. ${ }^{2,4,9-11}$ The ability to design materials with unusual properties is therefore a key focus of the field: can we understand these elastic anomalies so that we can tune the magnitude and/or range of negative responses?

Negative thermal expansion may occur in one, two, or all principal directions without violating thermodynamics. ${ }^{12,13}$ Thus, for example, the volume coefficient of thermal expansion (CTE), $\alpha_{V}=\frac{1}{V}\left(\frac{\partial V}{\partial T}\right)_{p}$, takes large negative values in zirconium tungstate $\mathrm{ZrW}_{2} \mathrm{O}_{8}$ and zinc(II) cyanide $\mathrm{Zn}(\mathrm{CN})_{2}$ over large temperature ranges. ${ }^{14}$ Under hydrostatic pressure, however, volume must always reduce and so the volume compressibility $\left(K_{V}=-\frac{1}{V}\left(\frac{\partial V}{\partial p}\right)_{T}\right.$, conventionally formulated as the bulk modulus, $\left.B=\left(K_{V}\right)^{-1}\right)$, must be definite and positive. ${ }^{15}$ Expansion under pressure can occur in one or two directions, as long as this is coupled to volume reduction. ${ }^{5,12,16}$ Therefore, negative linear compressibility (NLC) - the expansion in one principal direction of a material under hydrostatic pressure-is conceptually and empirically related to linear-NTE. In both cases, anomalous response relies on mechanical anisotropy. The so-called "wine-rack" model is often invoked where mechanical hinging allows linear expansion coupled to volume reduction on increasing pressure or decreasing temperature. ${ }^{5,8}$

Attention in this field has focused on a class of materials known as coordination polymers (CPs), in particular due to the very large magnitude of responses found in comparison to conventional oxide-based materials. ${ }^{7}$ Examples that show large NTE and NLC include cyanide frameworks such as $\mathrm{Ag}_{3}[\mathrm{Co}-$ $\left.(\mathrm{CN})_{6}\right]$ (refs 17 and 18), $\mathrm{KMn}\left[\mathrm{Ag}(\mathrm{CN})_{2}\right]_{3}$ (refs 19 and 20), $\mathrm{Zn}\left[\mathrm{Au}(\mathrm{CN})_{2}\right]_{2}$ (refs 21 and 22), and metal-organic frameworks $^{23}$ (MOFs) such as MIL-53 (ref 24), UTSA-16 (ref 25), ZAG-4 (ref 26), and $\left[\mathrm{NH}_{4}\right]\left[\mathrm{Zn}(\mathrm{HCOO})_{3}\right]$ (ref 27). In many cases, mechanical response can be predicted in these systems by considering the framework as a set of rigid connectors and hinges, so-depending on geometry and topology-NTE or

Received: December 9, 2019

Revised: February 11, 2020

Published: March 4, 2020 
NLC can be targeted. ${ }^{8,28}$ Despite no formal relationship between the two phenomena ${ }^{15}$ (with at least one known example violating the correspondence, ref 29), the correspondence of NTE and NLC is found in many systems, and across several other structural mechanisms of anomalous mechanical response. ${ }^{5}$ While up to $3 \%$ of 13,621 materials with elastic data recently analyzed in the Materials Project database are predicted to have NLC, ${ }^{30}$ experimental reports of large and sustained NLC remain rare.

A promising family of NTE/NLC coordination polymers are dicyanometallates with the general formula $\mathrm{AM}\left[\mathrm{M}^{\prime}(\mathrm{CN})_{2}\right]_{3}(\mathrm{~A}$ = group 1 monocation; $\mathrm{M}=+2$ transition metal; $\left.\mathrm{M}^{\prime}=\mathrm{Ag}, \mathrm{Au}\right)$. These adopt trigonal structures that are related to $\mathrm{Ag}_{3}[\mathrm{Co}-$ $\left.(\mathrm{CN})_{6}\right]$ : in all cases, octahedral $\mathrm{M}^{2+}$ nodes are linked via the essentially linear $\left[\mathrm{M}^{\prime}(\mathrm{CN})_{2}\right]^{-}$cation into a simple cubic network. $^{20,31,32}$ Three of these frameworks interpenetrate, giving rise to a nanoporous framework with channels running in the $c$ direction (Figure 1). In the analogues of interest here,

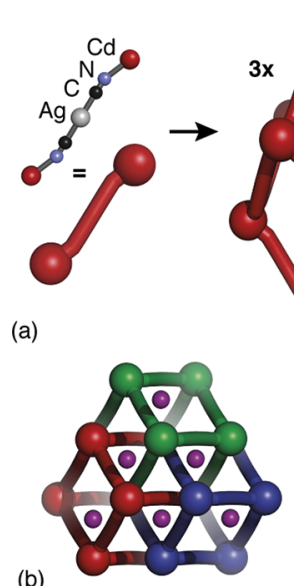

(c)
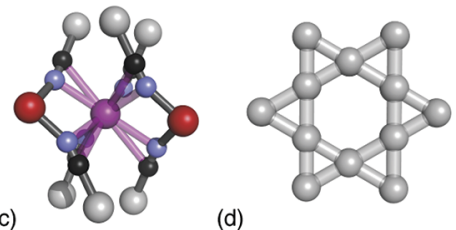

(d)

Figure 1. Structural features of potassium cadmium dicyanoargentate $\mathrm{KCd}\left[\mathrm{Ag}(\mathrm{CN})_{2}\right]_{3}$. (a) Each $\mathrm{Cd}^{2+}$ (red sphere) is coordinated to eight almost-linear $\left[\mathrm{Ag}(\mathrm{CN})_{2}\right]^{-}$linkers $\left(\mathrm{Ag}^{+}\right.$, silver spheres; C, black spheres; N, blue spheres), connected to form a distorted simple cubic net, as shown schematically in the center panel. Three such independent nets interpenetrate, shown right in contrasting colors for clarity. (b) Viewed down to the crystallographic c direction, potassium (purple spheres) is included in well-ordered channels within the structure. The distorted side-on cyanide octahedral coordination around each potassium is shown in part c. (d) The three interpenetrated nets are cross-linked by weak argentophilic interactions that form a distorted Kagomé sheet in the $\mathbf{a}-\mathbf{b}$ plane.

extra-framework $\mathrm{K}^{+}$cations are included within these channels. These $\mathrm{K}^{+}$cations have been found to induce soft-mode frustration in the structure which stabilizes the strong NLC response in $\mathrm{KMn}\left[\mathrm{Ag}(\mathrm{CN})_{2}\right]_{3}$ to much higher pressures than the cation-free $\mathrm{Ag}_{3}\left[\mathrm{Co}(\mathrm{CN})_{6}\right]\left(\equiv \mathrm{Co}\left[\mathrm{Ag}(\mathrm{CN})_{2}\right]_{3}\right)$ up to 2.2 $\mathrm{GPa}$ at least; cf. $0.19 \mathrm{GPa}$ in the parent compound. ${ }^{18,19}$ A variety of cations can be found within-and reversibly interand de-intercalated into ${ }^{33}$ - materials from the wider structural family. ${ }^{32}$ Here we refer to these materials as stabilized cyanometallate coordination polymers to highlight their importance in investigating anomalous pressure responses in particular.

Our previous study of $\mathrm{KMn}\left[\mathrm{Ag}(\mathrm{CN})_{2}\right]_{3}$ (ref 19) did not report any phase transition behavior, so it was not possible to identify the mechanism of NLC. High-pressure studies have been previously utilized to identify the critical behavior of NTE material $\mathrm{Zn}(\mathrm{CN})_{2}$ (ref 34), where phase transitions can be used to reveal the lowest-energy distortions driving mechanical response under changes in temperature or pressure. In the present study, the isostructural $\mathrm{KCd}\left[\mathrm{Ag}(\mathrm{CN})_{2}\right]_{3}$ is investigated to much higher pressures and across three phase transitions. Here we use high-pressure IR and Raman spectroscopy, singlecrystal and powder diffraction measurements, and firstprinciples calculations to investigate the pressure response of $\mathrm{KCd}\left[\mathrm{Ag}(\mathrm{CN})_{2}\right]_{3}$ in detail. We identify two main phase transitions up to $4 \mathrm{GPa}$ and solve the distorted structures based on powder and single-crystal X-ray diffraction. The sequence of structures observed is fully consistent with our IR and Raman spectroscopic results; indeed, such spectroscopic measurements directly probe the change in dominant vibrational modes of the framework with increasing pressure that complements our structural studies. First-principles calculations permit the identification of spectral regions of interest and the specific vibrational modes affected by structural transformation.

There is good reason to expect this material to show enhanced NLC compared to $\mathrm{KMn}\left[\mathrm{Ag}(\mathrm{CN})_{2}\right]_{3}$, as it exhibits one of the largest NTE effects among isostructural dicyanometallates. ${ }^{20}$ In this wider family of materials, the maximized flexibility can be attributed to (i) the large, geometrically flexible $\mathrm{Cd}^{2+}$ cations ${ }^{35}$ and (ii) the presence of weak argentophilic interactions. ${ }^{36}$ Both of these factors minimize the energy of deformation, while retention of potassium within the framework is expected to stabilize the framework from collapse. We find large and persistent NLC over the whole pressure range investigated. Our study concludes by highlighting key factors in the design of NLC coordination polymers-in particular the need to balance mechanical flexibility (to enhance the magnitude of response) with pressure stability (to increase the pressure range of response)-and commenting on wider implications, including the utility of combining techniques to give a full understanding of the mechanism, ${ }^{37}$ and on future directions in the design of flexible materials with anomalous mechanical response. ${ }^{23^{\circ}}$

\section{EXPERIMENTAL SECTION}

Synthesis of $\mathrm{KCd}\left[\mathrm{Ag}(\mathrm{CN})_{2}\right]_{3}$ Single Crystals. Highquality single crystals of $\mathrm{KCd}\left[\mathrm{Ag}(\mathrm{CN})_{2}\right]_{3}$ were synthesized by cold layering of concentrated solutions of $\mathrm{Cd}\left(\mathrm{NO}_{3}\right)_{2} \cdot 4 \mathrm{H}_{2} \mathrm{O}$ and $\mathrm{KAg}(\mathrm{CN})_{2}$ in $\mathrm{H}_{2} \mathrm{O}$, following a similar procedure to that described in refs 20 and 38. Large single crystals were synthesized using an $\mathrm{H}$-tube. Solutions were prepared by dissolving $187.6 \mathrm{mg}(1.00 \mathrm{mmol})$ of $\mathrm{KAg}(\mathrm{CN})_{2}$ (SigmaAldrich, $99 \%)$ and $102.5 \mathrm{mg}(0.33 \mathrm{mmol})$ of $\mathrm{Cd}\left(\mathrm{NO}_{3}\right)_{2} \cdot 4$ $\mathrm{H}_{2} \mathrm{O}$ (Sigma-Aldrich, 98\%) in $3 \mathrm{~mL}$ of $\mathrm{H}_{2} \mathrm{O}$ which were then carefully placed in separate arms of the $\mathrm{H}$-tube and chilled. Chilled water was carefully layered on top until the $\mathrm{H}$-tube was filled and left for several days, yielding triangular single crystals of $\mathrm{KCd}\left[\mathrm{Ag}(\mathrm{CN})_{2}\right]_{3}$. Synthesis of a large sample of small crystals was also possible by careful layering of concentrated solutions in a test tube. As the product was previously reported to be light-sensitive, ${ }^{20}$ all reactions were left in the dark and products were kept in sample vials wrapped in foil.

High-Pressure Single-Crystal Raman Spectroscopy. Variable-pressure Raman experiments were performed using a membrane diamond anvil cell (DAC). The cell was placed under the Mitutoyo 50x objective on an Olympus microscope coupled to a Jobin-Yvon T64000 spectrometer equipped with a triple monochromator. The $676.4 \mathrm{~nm}$ line of a $\mathrm{Kr}^{+}$laser was 
used for excitation. A single crystal was loaded in the preindented hole of a stainless steel gasket along with a ruby sphere as a pressure calibrant, and glycerol was used as a pressure-transmitting medium. ${ }^{39}$ The pressure was measured based on the shift of the ruby $\mathrm{R}_{1}$ fluorescence line. A range of nonpenetrating media were used in our studies, as the commonly used 4:1 methanol:ethanol mixture was found in a preliminary test to react with the sample at high pressure, similar to what is observed in $\mathrm{Zn}(\mathrm{CN})_{2} \cdot{ }^{34,40}$

High-Pressure Far-Infrared Spectroscopy. Far-IR experiments were performed using a membrane DAC on a Bruker instruments IFS66v/s Fourier transform infrared spectrometer (FTIR) equipped with a Ge-coated Mylar $(6 \mu \mathrm{m})$ beamsplitter and a bolometer detector. The spectra were recorded over the $35-600 \mathrm{~cm}^{-1}$ range with a resolution of $2 \mathrm{~cm}^{-1}$ with 400 scans per spectrum. A double condenser system (Cassegrain objectives $15 \times$, numerical aperture 0.4 ) was used. Single crystals were ground and mixed with polyethylene, which was used to dilute the sample. This mixture was then loaded in the preindented hole of a gasket along with a ruby sphere as for Raman experiments.

High-Pressure Single-Crystal X-ray Diffraction. Singlecrystal X-ray diffraction measurements at high pressure were performed using a Rigaku Oxford Diffraction (Agilent) Gemini-S Diffractometer (Mo K $\alpha 1, \lambda=0.0 .71073 \AA$ ) equipped with a Sapphire CCD detector at $65.00 \mathrm{~mm}$ from the sample. The same crystal was also studied at room pressure on a Rigaku Oxford Diffraction (Agilent) X'calibur diffractometer. A $170 \times 80 \times 30 \mu \mathrm{m}^{3}$ single-crystal plate was fixed to one anvil of a Merrill-Bassett DAC equipped with Boehler-Almax diamonds along with a ruby microsphere for pressure calibration. The opening angle of the cell was $80^{\circ}$ to give maximum access to reciprocal space during data collection. A tungsten gasket was placed on the other anvil, Daphne7474 $\mathrm{oil}^{41}$ was added as a pressure transmitting medium, and the two parts of the cell were then assembled. Data collection, indexing, and reduction were performed using CrysAlisPro (Agilent) software along with absorption correction for the ambient-pressure data. High-pressure data were corrected for absorption using Absorb7.0. ${ }^{42}$ Structure refinements were performed using SHELXL97. ${ }^{43}$ Structural models for the highpressure phases were obtained based on the structure of the ambient pressure phase and the observed group-subgroup relationships based on the unit cells and space groups of the high-pressure phases. ${ }^{44} \mathrm{C}$ and $\mathrm{N}$ atom positions were located using difference Fourier maps. The $\mathrm{C}-\mathrm{N}$ distance was constrained in all refinements, making use of the average value determined in the ambient-pressure phase. Due to the large number of variables for the two high-pressure phases, the $\mathrm{Ag}-\mathrm{C}$ and $\mathrm{Cd}-\mathrm{N}$ distances were also constrained. $\mathrm{C}$ and $\mathrm{N}$ atoms were treated using isotropic displacement parameters for the high-pressure data sets.

High-Pressure Synchrotron Powder X-ray Diffraction. Several $\mathrm{KCd}\left[\mathrm{Ag}(\mathrm{CN})_{2}\right]_{3}$ single crystals were ground to a very fine powder and placed in the preindented and drilled cavity of a stainless steel gasket in an ETH Diamond Anvil Cell. A ruby microsphere was added to measure the pressure, and silicon oil was used as the pressure transmitting medium. X-ray diffraction data were obtained on beamline BM01A (SwissNorwegian beamline) at the ESRF. A wavelength of $0.69412 \AA$ was selected using a $\mathrm{Si}(111)$ monochromator with a $100 \mu \mathrm{m}$ focused beam-size. Data were collected using a MAR345 image plate placed at $\sim 250 \mathrm{~mm}$ from the sample. Calibration and integration of the images were performed using FIT2D. ${ }^{45}$ Pawley fits to data were performed using TOPAS Academic $\mathrm{v} 4.1^{46}$ at each pressure using space groups as determined from single-crystal experiments using a single $\mathrm{TCHZ}$ peak shape. ${ }^{47}$ Rietveld refinement was not possible due to the extreme preferred orientation within the pressure cell, especially at low pressure.

Computational Methods. First-principles calculations were performed within the density functional theory framework, as implemented in the ABINIT package. ${ }^{48}$ The exchange-correlation energy functional is evaluated using the local density approximation parametrized by Perdew and Wang. ${ }^{49}$ The all-electron potentials are replaced by normconserving pseudopotentials generated according to the Troullier-Martins scheme. ${ }^{50} \mathrm{~K}\left(4 \mathrm{~s}^{1}\right), \mathrm{Cd}\left(4 \mathrm{~d}^{10}, 5 \mathrm{~s}^{2}\right), \operatorname{Ag}\left(4 \mathrm{~d}^{10}\right.$, $\left.5 s^{1}\right), C\left(2 s^{2}, 2 p^{2}\right)$, and $\mathrm{N}\left(2 s^{2}, 2 p^{3}\right)$ electrons are considered as valence states. The electronic wave functions were expanded in plane waves up to a kinetic energy cutoff of $56 \mathrm{Ha}$, and integrals over the Brillouin zone were approximated by sums over a $6 \times 6 \times 6$ mesh of special $k$-points according to the Monkhorst-Pack scheme. ${ }^{51}$ Atomic relaxation was performed at the experimental lattice parameters until the maximum residual forces on each atom were less than $6 \mathrm{Ha} / \mathrm{Bohr}$.

Dynamical matrix, dielectric constants, and Born effective charges were calculated within a variational approach to density functional perturbation theory. ${ }^{52}$ The Raman susceptibility tensors were obtained within a nonlinear response formalism, making use of the $2 n+1$ theorem. The infrared transmittance and Raman spectra were calculated as described in refs 53 and 54, respectively.

\section{RESULTS AND ANALYSIS}

Calculated Raman and IR Spectra. $\operatorname{KCd}\left[\operatorname{Ag}(\mathrm{CN})_{2}\right]_{3}$ belongs to the $D_{3}$ point group. The zone-center optical phonons can be therefore classified according to the irreducible representations of this group as $\Gamma_{\mathrm{opt}}=7 \mathrm{~A}_{1}+9 \mathrm{~A}_{2}+16 \mathrm{E}$. The doubly degenerate $\mathrm{E}$-modes polarized in the $x y$ plane are both Raman and infrared active, while the $\mathrm{A}_{2}$-modes polarized along $z$ are only infrared active. The $A_{1}$-modes are Raman active. Close to the $\Gamma$-point, the macroscopic electric field splits the polar active modes into transverse (TO) and longitudinal (LO) modes. These calculated modes are listed in Table 1 along with their symmetry. We note that the LO-TO splitting is negligible for all modes except for the $\mathrm{A}_{2}(\mathrm{TO})$ mode at 146 $\mathrm{cm}^{-1}$ and the $\mathrm{E}(\mathrm{TO})$ mode at $169 \mathrm{~cm}^{-1}$ where this splitting can be as large as $26 \mathrm{~cm}^{-1}$.

Infrared and Raman spectra have also been calculated on a polycrystalline powder and are compared in Figure 2 with the experimental results. Calculated frequencies are systematically slightly upshifted with respect to the experiment due to the significant difference of temperature between the calculation $(0 \mathrm{~K})$ and the experiment $(295 \mathrm{~K})$. Calculated relative infrared and Raman intensities are in good agreement with the corresponding experimental ones. Based on this good agreement, we assigned the experimental features to specific phonon modes (see Table 1).

High-Pressure Single-Crystal Raman Results. Vibrational modes in three spectral regions were investigated under pressure: $25-80,170-460$, and $2160-2190 \mathrm{~cm}^{-1}$ (Figure 3). These ranges correspond to translational lattice modes of the cations, lattice modes of the cyanide anions, and internal stretching modes of the cyanide anions, respectively. Beginning with the two observed internal modes in the high-frequency 
Table 1. Calculated and Experimental Zone-Center Optical Frequencies $\left(\right.$ in $\mathrm{cm}^{-1}$ )

\begin{tabular}{|c|c|c|c|c|c|}
\hline \multirow[b]{2}{*}{ sym. } & \multicolumn{2}{|c|}{ Calc. $(0 \mathrm{~K})$} & \multicolumn{2}{|c|}{ Exp. $(295 \mathrm{~K})$} & \multirow[b]{2}{*}{ approximate assignment } \\
\hline & $\mathrm{TO}$ & LO & IR & Raman & \\
\hline $\mathrm{E}$ & 38 & 38 & & & $\begin{array}{l}\text { antisym. translation } \\
\mathrm{Cd}-\mathrm{NC}-\mathrm{Ag}-\mathrm{CN}-\mathrm{Cd}\end{array}$ \\
\hline $\mathrm{A}_{2}$ & 39 & 39 & & & libration $\mathrm{Ag}-\mathrm{Ag}-\mathrm{Ag}$ \\
\hline $\mathrm{E}$ & 44 & 45 & & 52 & motion $\mathrm{Cd}-\mathrm{NC}-\mathrm{Ag}-\mathrm{CN}-\mathrm{Cd}$ \\
\hline $\mathrm{A}_{1}$ & 51 & & & 70 & breathing $\mathrm{Ag}-\mathrm{Ag}-\mathrm{Ag}$ \\
\hline $\mathrm{A}_{2}$ & 73 & 74 & & & twisting $\mathrm{CN}-\mathrm{K}-\mathrm{NC}$ \\
\hline $\mathrm{E}$ & 84 & 84 & & & twisting $\mathrm{CN}-\mathrm{K}-\mathrm{NC}$ \\
\hline $\mathrm{E}$ & 100 & 100 & 106 & & twisting $\mathrm{CN}-\mathrm{K}-\mathrm{NC}$ \\
\hline $\mathrm{A}_{2}$ & 102 & 104 & & & $\begin{array}{l}\text { wagging } \mathrm{CN}-\mathrm{Ag}-\mathrm{NC}+ \\
\text { scissoring } \mathrm{K}-\mathrm{N}-\mathrm{Cd}\end{array}$ \\
\hline $\mathrm{E}$ & 116 & 117 & & & $\begin{array}{l}\text { wagging } \mathrm{CN}-\mathrm{Ag}-\mathrm{NC}+ \\
\text { scissoring } \mathrm{K}-\mathrm{N}-\mathrm{Cd}\end{array}$ \\
\hline $\mathrm{A}_{1}$ & 119 & & & & wagging $\mathrm{NC}-\mathrm{Ag}-\mathrm{CN}$ \\
\hline $\mathrm{E}$ & 138 & 146 & 144 & & wagging $\mathrm{K}-\mathrm{N}-\mathrm{Cd}$ \\
\hline $\mathrm{A}_{2}$ & 146 & 172 & & & wagging $\mathrm{K}-\mathrm{N}-\mathrm{Cd}$ \\
\hline $\mathrm{E}$ & 158 & 161 & & & wagging $\mathrm{CN}-\mathrm{Ag}-\mathrm{NC}$ \\
\hline $\mathrm{E}$ & 169 & 192 & 172 & 176 & wagging $\mathrm{CN}-\mathrm{Ag}-\mathrm{NC}$ \\
\hline $\mathrm{A}_{1}$ & 186 & & & & wagging $\mathrm{CN}-\mathrm{Ag}-\mathrm{NC}$ \\
\hline $\mathrm{A}_{2}$ & 198 & 200 & 197 & & wagging $\mathrm{CN}-\mathrm{Ag}-\mathrm{NC}$ \\
\hline $\mathrm{E}$ & 277 & 277 & 278 & 259 & $\begin{array}{l}\text { twisting } \mathrm{C}-\mathrm{Ag}-\mathrm{C}+\text { scissoring } \\
\mathrm{N}-\mathrm{K}-\mathrm{N}\end{array}$ \\
\hline $\mathrm{A}_{2}$ & 279 & 280 & & & $\begin{array}{l}\text { twisting } \mathrm{C}-\mathrm{Ag}-\mathrm{C}+\text { scissoring } \\
\mathrm{N}-\mathrm{K}-\mathrm{N}\end{array}$ \\
\hline $\mathrm{E}$ & 293 & 294 & 292 & 276 & $\begin{array}{l}\text { twisting } \mathrm{C}-\mathrm{Ag}-\mathrm{C}+\text { scissoring } \\
\mathrm{N}-\mathrm{K}-\mathrm{N}\end{array}$ \\
\hline$A_{1}$ & 303 & & & 288 & $\begin{array}{l}\text { wagging } \mathrm{C}-\mathrm{Ag}-\mathrm{C}+\text { scissoring } \\
\mathrm{N}-\mathrm{K}-\mathrm{N}\end{array}$ \\
\hline $\mathrm{E}$ & 317 & 318 & 315 & & $\begin{array}{l}\text { wagging } \mathrm{C}-\mathrm{Ag}-\mathrm{C}+\text { scissoring } \\
\mathrm{N}-\mathrm{K}-\mathrm{N}\end{array}$ \\
\hline $\mathrm{A}_{2}$ & 335 & 335 & & & $\begin{array}{l}\text { wagging } \mathrm{C}-\mathrm{Ag}-\mathrm{C}+\text { scissoring } \\
\mathrm{N}-\mathrm{K}-\mathrm{N}\end{array}$ \\
\hline $\mathrm{E}$ & 343 & 343 & & 352 & $\begin{array}{l}\text { wagging } \mathrm{C}-\mathrm{Ag}-\mathrm{C}+\text { scissoring } \\
\mathrm{N}-\mathrm{K}-\mathrm{N}\end{array}$ \\
\hline $\mathrm{A}_{1}$ & 347 & & & 369 & $\begin{array}{l}\text { wagging } \mathrm{C}-\mathrm{Ag}-\mathrm{C}+\text { scissoring } \\
\mathrm{N}-\mathrm{K}-\mathrm{N}\end{array}$ \\
\hline $\mathrm{E}$ & 384 & 384 & & 381 & twisting $\mathrm{CN}-\mathrm{K}-\mathrm{NC}$ \\
\hline $\mathrm{A}_{2}$ & 440 & 449 & 418 & & scissoring $\mathrm{CN}-\mathrm{K}-\mathrm{NC}$ \\
\hline$A_{1}$ & 445 & & & 430 & scissoring $\mathrm{N}-\mathrm{K}-\mathrm{N}$ \\
\hline $\mathrm{E}$ & 447 & 449 & 452 & & twisting $\mathrm{CN}-\mathrm{K}-\mathrm{NC}$ \\
\hline $\mathrm{E}$ & 2183 & 2185 & & & stretching $\mathrm{C}-\mathrm{N}$ \\
\hline $\mathrm{A}_{2}$ & 2184 & 2192 & & & stretching $\mathrm{C}-\mathrm{N}$ \\
\hline $\mathrm{E}$ & 2191 & 2192 & & 2167 & stretching $\mathrm{C}-\mathrm{N}$ \\
\hline$A_{1}$ & 2199 & & & 2167 & stretching $\mathrm{C}-\mathrm{N}$ \\
\hline
\end{tabular}

range, the modes first increase in wavenumber as a function of pressure, which might be tentatively interpreted as being due to compression of the $\mathrm{C}-\mathrm{N}$ bond. A discontinuous increase occurs just above $0.42 \mathrm{GPa}$ above which the modes continue to shift to higher wavenumbers. A second discontinuity occurs above $2.4 \mathrm{GPa}$, with, in this case, an abrupt decrease in wavenumber. The modes subsequently increase in wavenumber with further increases in pressure, and the higher wavenumber mode becomes unresolvable just above $5 \mathrm{GPa}$. These results indicate that above the first discontinuity the C$\mathrm{N}$ bond length decreases, whereas the second discontinuity corresponds to a rearrangement, resulting in an increase in bond length. In the intermediate spectral range $\left(170-460 \mathrm{~cm}^{-1}\right)$, most modes increase in wavenumber as expected. At $0.42 \mathrm{GPa}$, major changes occur, for example, the two modes at 354 and $385 \mathrm{~cm}^{-1}$ are replaced by a single mode at $370 \mathrm{~cm}^{-1}$. In addition, the wavenumbers of the three modes

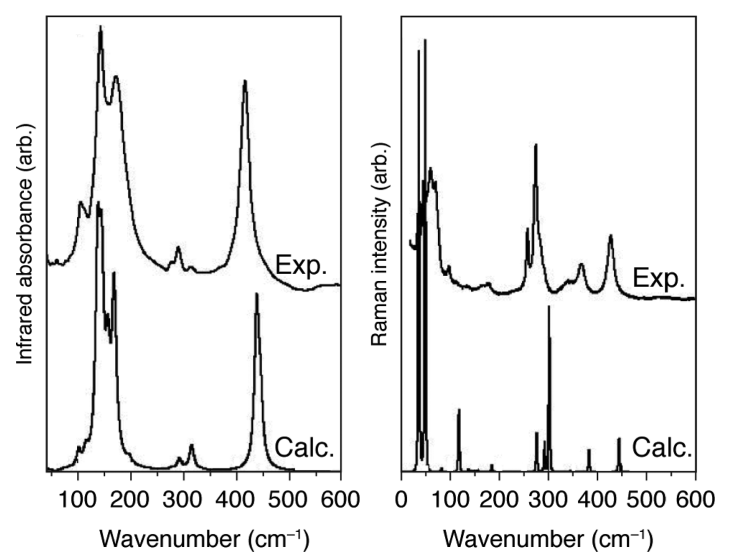

Figure 2. Calculated and experimental (left) infrared absorbance and (right) Raman scattering spectra in the low- and mid-frequency spectral range $\left(<600 \mathrm{~cm}^{-1}\right)$. A Lorentzian line shape and a constant line width fixed at $5 \mathrm{~cm}^{-1}$ in the calculated spectra are assumed.

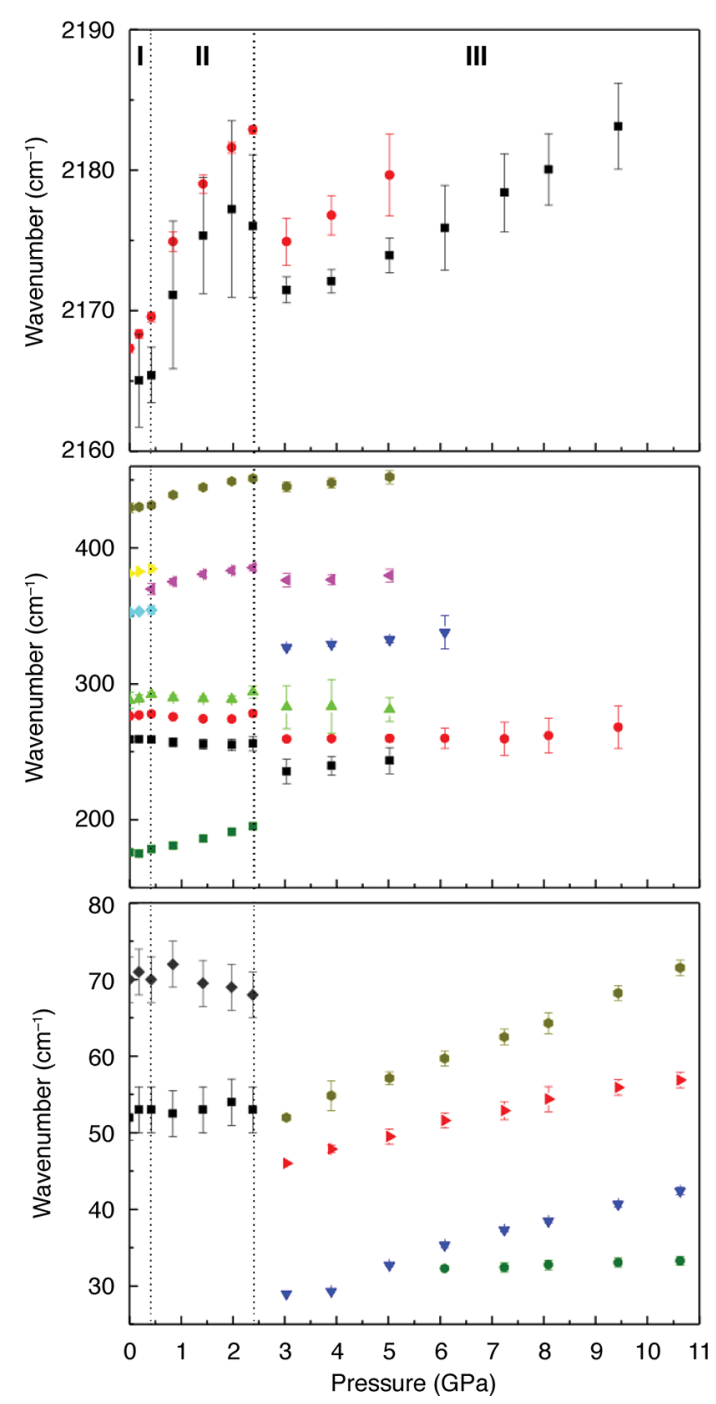

Figure 3. Pressure dependence of the Raman modes of $\mathrm{KCd}[\mathrm{Ag}$ $\left.(\mathrm{CN})_{2}\right]_{3}$ in the low-, mid-, and high-frequency spectral ranges investigated. Two phase transitions at 0.42 and $2.4 \mathrm{GPa}$ are evident by the splitting of modes and shifting of Raman frequencies.

in the $250-300 \mathrm{~cm}^{-1}$ range shift slightly to lower wavenumbers. More abrupt changes occur above $2.4 \mathrm{GPa}$ with 
discontinuous shifts of most modes to lower wavenumber and the disappearance of the mode near $195 \mathrm{~cm}^{-1}$ and the appearance of a new mode near $327 \mathrm{~cm}^{-1}$.

Somewhat different behavior is observed in the lowest wavenumber lattice mode region. The two initial broad bands are stable or vary only slightly with pressure. No apparent change occurs near $0.42 \mathrm{GPa}$; however, the spectrum completely changes above $2.4 \mathrm{GPa}$. Broad weak bands are replaced by a series of sharp lattice modes, which exhibit a normal increase in wavenumber with pressure due to the decrease in volume. The lowest wavenumber mode is found to split above $6 \mathrm{GPa}$.

The spectral changes that occur at 0.42 and $2.4 \mathrm{GPa}$ are evidence for phase transitions in $\mathrm{KCd}\left[\mathrm{Ag}(\mathrm{CN})_{2}\right]_{3}$ at high pressure. The lower pressure transition principally affects the modes of the cyanide groups and may be linked to a reorientation of these groups without strongly modifying the cation sublattice, as no changes are observed in the cation lattice mode region. The second transition is more abrupt, and the changes in the cation lattice mode region are an indication of a possible rearrangement of the metal sublattice. It is clear that our spectroscopic measurements are very sensitive to both bond lengths (which may be verified, to a certain extent, by crystallographic studies) and the bonding character of the coordination network. Cyanide-metal multiple bonding is known to be significant in many transition-metal cyanide complexes, especially those which involve the metal in a low oxidation state. $^{55,56}$

High-Pressure Far-Infrared Results. Eight low-wavenumber bands in the $40-650 \mathrm{~cm}^{-1}$ region could be studied at high pressure in the far-infrared. As in the case of Raman spectra, significant vibrational discontinuities are identified above $0.5 \mathrm{GPa}$ and between 2 and $3 \mathrm{GPa}$, as presented in Figure 4 and Figure SI1. The lowest frequency range (below $175 \mathrm{~cm}^{-1}$ ), where vibrations are assigned to lattice modes involving potassium cations (Table 1 ), is the most sensitive to phase transitions. Above $0.5 \mathrm{GPa}$, a first discontinuity is observed leading to an increase in wavenumber with pressure for all of these lattice modes. Above $2 \mathrm{GPa}$, the original $\mathrm{K}-\mathrm{N}-$ $\mathrm{Cd}$ wag modes split into two components around 146 and $156 \mathrm{~cm}^{-1}$. The $\mathrm{CN}-\mathrm{K}-\mathrm{CN}$ twist modes $\left(107 \mathrm{~cm}^{-1}\right.$ at $p_{\text {amb }}$ ) become very weak above $2.6 \mathrm{GPa}$ and can no longer be followed above $3 \mathrm{GPa}$; concomitantly, a new band appears at $88 \mathrm{~cm}^{-1}$ (Figure 4).

At higher frequencies, the $\mathrm{CN}-\mathrm{Ag}-\mathrm{CN}$ wagging $\left(172 \mathrm{~cm}^{-1}\right.$ at $\left.p_{\text {amb }}\right)$ vibrations are sensitive both to the first and second phase transitions. At pressures above $0.5 \mathrm{GPa}$, there is a significant increase of the wavenumber dependence on pressure; between 2 and $3 \mathrm{GPa}$, the frequency behavior is independent of the pressure. The band position subsequently shifts, and a new feature around $200 \mathrm{~cm}^{-1}$ appears above $3 \mathrm{GPa}$.

The $\mathrm{C}-\mathrm{Ag}-\mathrm{C}$ twisting $+\mathrm{N}-\mathrm{K}-\mathrm{N}$ scissoring $\left(279 \mathrm{~cm}^{-1}\right)$ vibrations also disappear around $2.5 \mathrm{GPa}$, and a new band appears around $256 \mathrm{~cm}^{-1}$. Surprisingly, modes that have the same origin at higher frequencies $\left(291\right.$ and $315 \mathrm{~cm}^{-1}$ at $\left.p_{\mathrm{amb}}\right)$ only show a slight sensitivity to pressure discontinuities. Finally, for the scissoring $\mathrm{CN}-\mathrm{K}-\mathrm{NC}$ vibrations $\left(418 \mathrm{~cm}^{-1}\right.$ at $\left.p_{\mathrm{amb}}\right)$, at $0.5 \mathrm{GPa}$, the band significantly upshifts and further abrupt changes occur between 2 and $3 \mathrm{GPa}$. Above this pressure, the band frequency increases monotonically. These observations are consistent with the Raman results and clearly indicate that important structural changes occur around 0.5

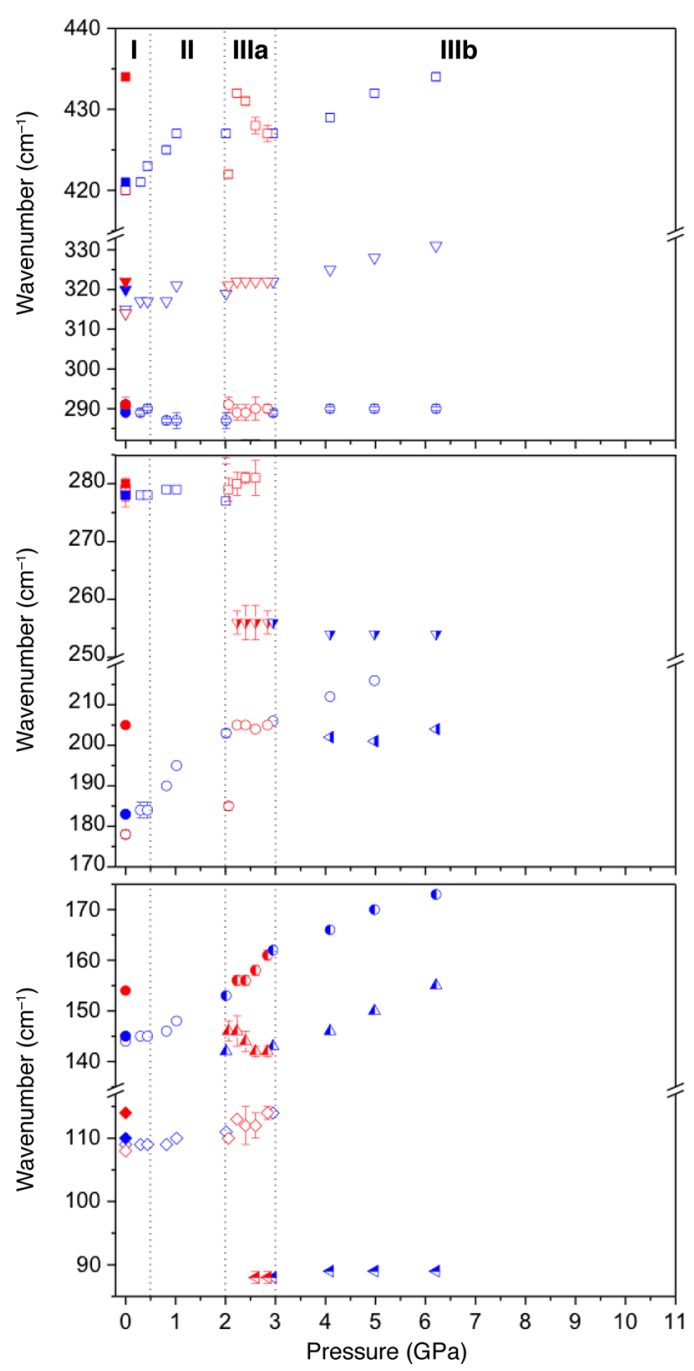

Figure 4. Pressure dependence of the far IR modes of $\mathrm{KCd}[\mathrm{Ag}-$ $\left.(\mathrm{CN})_{2}\right]_{3}$. Red and blue symbols represent two independent sets of experiments. Filled symbols correspond to measurements upon pressure release, and half filled symbols, to new modes appearing after phase transitions. The two phase transitions at $\sim 0.5$ and $\sim 2 \mathrm{GPa}$ are evident by the splitting of modes and shifting of infrared frequencies; a third transition is possible at $\sim 3 \mathrm{GPa}$. Uncertainties that are not represented by error bars are smaller than the symbol size. The pressure axis is extended to $11 \mathrm{GPa}$ to directly compare the data to the Raman results.

and above $2 \mathrm{GPa}$ that strengthen bonding interactions between $\mathrm{CN}$ and $\mathrm{K}$.

High-Pressure X-ray Diffraction Results. The combined results from variable-pressure Raman and IR experiments suggest there are two main pressure-induced phase transitions in $\mathrm{KCd}\left[\mathrm{Ag}(\mathrm{CN})_{2}\right]_{3}$ : one at around $0.5 \mathrm{GPa}$ and the other above $2 \mathrm{GPa}$. We therefore turn our attention to crystallographic measurements to characterize (i) the bulk mechanical behavior of this material, (ii) the microscopic origin of response, and (iii) the nature of these new phases. The complementary nature of single-crystal and powder diffraction data is exploited to give a full structural description, and we correlate these structural changes with the major modifications observed in our spectroscopic data. The appearance of superlattice reflections in our diffraction experiments confirms the I $\rightarrow$ II transition occurs at $0.56(10) \mathrm{GPa}<p<0.68(10)$ $\mathrm{GPa}$, and structural refinement shows this is a displacive phase 
transition, resulting in a doubling of the unit cell in $c$. Above 2.25 $\mathrm{GPa}$-in both powder and single-crystal experimentsthere is a large change in the diffraction pattern observed due to a reconstructive phase transition to $\mathrm{KCd}\left[\mathrm{Ag}(\mathrm{CN})_{2}\right]_{3}$-III with a monoclinic unit cell.

i. Compressibilities and Structural Changes of Phases I and II. At the first single-crystal high-pressure point at 0.59 $\mathrm{GPa}$, the structure could still be refined based on the model of the trigonal ambient pressure phase and no superlattice reflections were observed. A degree of negative linear compressibility was observed in the c direction, which is more fully characterized by fitting to the larger number of lattice parameters extracted from powder diffraction data described below. This expansion is coupled to very strong compression in the $\mathbf{a}-\mathbf{b}$ plane.

At this first pressure point, the following observations can be made. The $\mathrm{N}-\mathrm{Cd}-\mathrm{N}$ angles oriented along the $c$ direction decrease from $87.0(1)$ to $85(1)^{\circ}$, with a corresponding increase in the out-of-plane $\mathrm{N}-\mathrm{N}$ distances in the $\left[\mathrm{CdN}_{6}\right]$ octahedra by almost $3 \%$. In addition, there is a closing of $\mathrm{Cd}-$ $\mathrm{N}-\mathrm{K}$ angle and increase in some $\mathrm{N}-\mathrm{Cd}-\mathrm{N}$ angles and $\mathrm{N}-\mathrm{K}-$ $\mathrm{N}$ angles. This results in a significant decrease in the distance between $\left[\mathrm{CdN}_{6}\right]$ octahedra, particularly in the $\mathbf{a}-\mathbf{b}$ plane, that can be linked to a wine-rack folding mechanism between the layers containing the $\left[\mathrm{CdN}_{6}\right]$ octahedra. Meanwhile, it is found that the $\mathrm{Cd}-\mathrm{N}$ distances do not change within experimental error between ambient pressure and $0.59 \mathrm{GPa}$. Decreases in the $\mathrm{Ag}-\mathrm{C}$ and $\mathrm{K} \cdots \mathrm{N}$ distances are observed but are of the order of 2 esds in the high-pressure data; these distances do also have an important component in the $\mathbf{a}-\mathbf{b}$ plane.

Upon further increase in pressure to $1.6 \mathrm{GPa}$, a large number of superlattice reflections $h k l(l=n / 2)$ were observed. The vast majority of these reflections could be indexed based on a P312 cell, which is doubled along the $\mathrm{c}$ direction. Fewer than 15 very weak superlattice reflections $h k l$ with a maximum relative intensity of about $0.3 \%$ were also observed with $h=n / 2$ and/ or $k=n / 2$, indicating that the unit cell is also doubled along the $\mathbf{a}$ and $\mathbf{b}$ directions. Due to the very low intensity of these reflections and the limited high-pressure data available, the structure was refined using the P312 cell doubled only along the $\mathrm{c}$ direction with the undistorted starting model. This new structure corresponds to a distortion of the initial structure with antiphase tilting of the $\left[\mathrm{CdN}_{6}\right]$ octahedra about $\mathrm{c}$, and thus provides a new compression mechanism for the material (Figure 5). The cell doubling along $\mathbf{a}$ and $\mathbf{b}$ probably is a result of slight additional tilts about $\mathbf{a}$ and $\mathbf{b}$. A summary of the single-crystal refinement is given in Table 2; full details for all refinements are given in the Supporting Information. A similar tilting phase transition was reported in zinc dicyanoaurate at
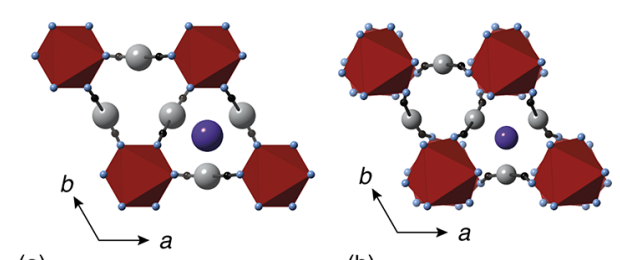

(a)

(b)

Figure 5. A doubling of the unit cell in the c direction allows antiphase octahedral tilts in $\operatorname{KCd}\left[\operatorname{Ag}(\mathrm{CN})_{2}\right]_{3}$. (a) The ambientpressure $P 312$ and (b) double-c phase II structure are shown down c. $\mathrm{Cd}$ are shown as red octahedra, and $\mathrm{C}, \mathrm{N}, \mathrm{Ag}$, and $\mathrm{K}$ shown as black, blue, silver, and purple spheres, respectively.
Table 2. Single-Crystal X-ray Diffraction Data Collection and Refinement Details for $\mathrm{KCd}\left[\mathrm{Ag}(\mathrm{CN})_{2}\right]_{3}$-II at $p=1.6$ GPa and Room Temperature ${ }^{a}$

\begin{tabular}{|c|c|c|c|c|}
\hline \multicolumn{3}{|c|}{ radiation } & \multicolumn{2}{|c|}{ Mo $\mathrm{K} \alpha, \lambda=0.71073 \AA$} \\
\hline & formula & & $\mathrm{KCdAg}_{3} \mathrm{C}_{6} \mathrm{~N}$ & \\
\hline & Z & & 2 & \\
\hline & crystal size $(\mu \mathrm{m})$ & & $170 \times 80 \times$ & \\
\hline & crystal system & & trigonal & \\
\hline & space group & & P312 & \\
\hline & $a(\AA)$ & & $6.497(2)$ & \\
\hline & $c(\AA)$ & & $17.00(2)$ & \\
\hline & $V\left(\AA^{3}\right)$ & & $621.4(8)$ & \\
\hline & $R\left(F_{\mathrm{obs}}>4 \sigma\right)$ & & 0.0743 & \\
\hline atom & $x$ & $y$ & $z$ & $U_{\text {eq }}\left(\times 10^{-2} \AA^{2}\right)$ \\
\hline $\mathrm{Cd}$ & 0 & 0 & $0.2546(7)$ & $2.7(1)$ \\
\hline $\mathrm{K}$ & 0.6667 & 0.3333 & $0.227(2)$ & $6.0(5)$ \\
\hline $\mathrm{Ag} 1$ & $0.4984(4)$ & $-0.0032(8)$ & 0 & $3.8(8)$ \\
\hline $\mathrm{Ag} 2$ & $0.4997(4)$ & $-0.0007(8)$ & 0.5 & $4.2(8)$ \\
\hline $\mathrm{N} 1$ & $0.728(6)$ & $1.014(6)$ & $0.167(2)$ & $4.1(7)^{b}$ \\
\hline $\mathrm{C} 1$ & $0.669(6)$ & $0.000(7)$ & $0.101(2)$ & $2.6(6)^{b}$ \\
\hline $\mathrm{N} 2$ & $0.686(5)$ & $0.965(5)$ & $0.666(2)$ & $4.1(7)^{b}$ \\
\hline $\mathrm{C} 2$ & $0.607(6)$ & $0.969(6)$ & $0.606(2)$ & $2.6(6)^{b}$ \\
\hline
\end{tabular}

${ }^{a}$ Estimated standard errors are given in parentheses. ${ }^{b}$ Refined isotropically.

high pressure, $^{22}$ and it would seem likely that many coordination frameworks may have similar phase transitions due to the large number of low-energy distortions availableleading to subtle peak splitting or cell doubling-to allow reduction of the framework (i.e., normalized unit cell $V / Z$ ) volume. $^{57,58}$ The challenge in high-pressure experiments is gaining enough intensity and resolution to resolve such distortions, where restraining the model to a higher symmetry is advantageous to reduce the number of variables in the refinement to increase robustness.

Lattice parameters were extracted by Pawley refinement of powder diffraction data at all pressure points in the lowpressure regime, making use of the space groups determined from single-crystal analysis. The variation in the lattice parameters (powder and single crystal) across all phases is presented in Figure 6. By fitting our variable-pressure lattice parameters for phases I and II using PASCal, ${ }^{59}$ we can extract the bulk mechanical response, as given in Table 3. For phase I, the small number of data points means the behavior is most robustly described using a linear fit to data. Such analysis reveals very large negative compressibility in the $\mathrm{c}$ direction of $K_{c}=-21(2) \mathrm{TPa}^{-1}$, the largest NLC yet found in this family of materials. The compensating PLC is $K_{a}=+48(8) \mathrm{TPa}^{-1}$, and fitting the unit cell volumes to a third-order Birch-Murnaghan $(B-M)$ equation of state shows rapid stiffening of the structure and a very small bulk modulus at low pressure.

Across the I/II phase boundary, there are no volume nor lattice parameter discontinuities (where $c_{\mathrm{II}}=2 c_{\mathrm{I}}$ ) due to the close relationship between the two phases and the continuous nature of the phase transition. Calculating compressibilities across both phases, $\mathrm{KCd}\left[\mathrm{Ag}(\mathrm{CN})_{2}\right]_{3}$ shows a very large NLC response, $K_{c}=-13.9(11) \mathrm{TPa}^{-1}$. B-M fitting for the two phases suggests both phases rapidly stiffen on application of pressure $\left(B^{\prime} \gg 4\right)$, but again, robust fits cannot be carried out. We can however show that the bulk moduli for both phases are lower than that for $\mathrm{KMn}\left[\mathrm{Ag}(\mathrm{CN})_{2}\right]_{3}$, with the second-order $B_{0}$ value of 13.6(10) GPa for phase II giving an upper bound for 

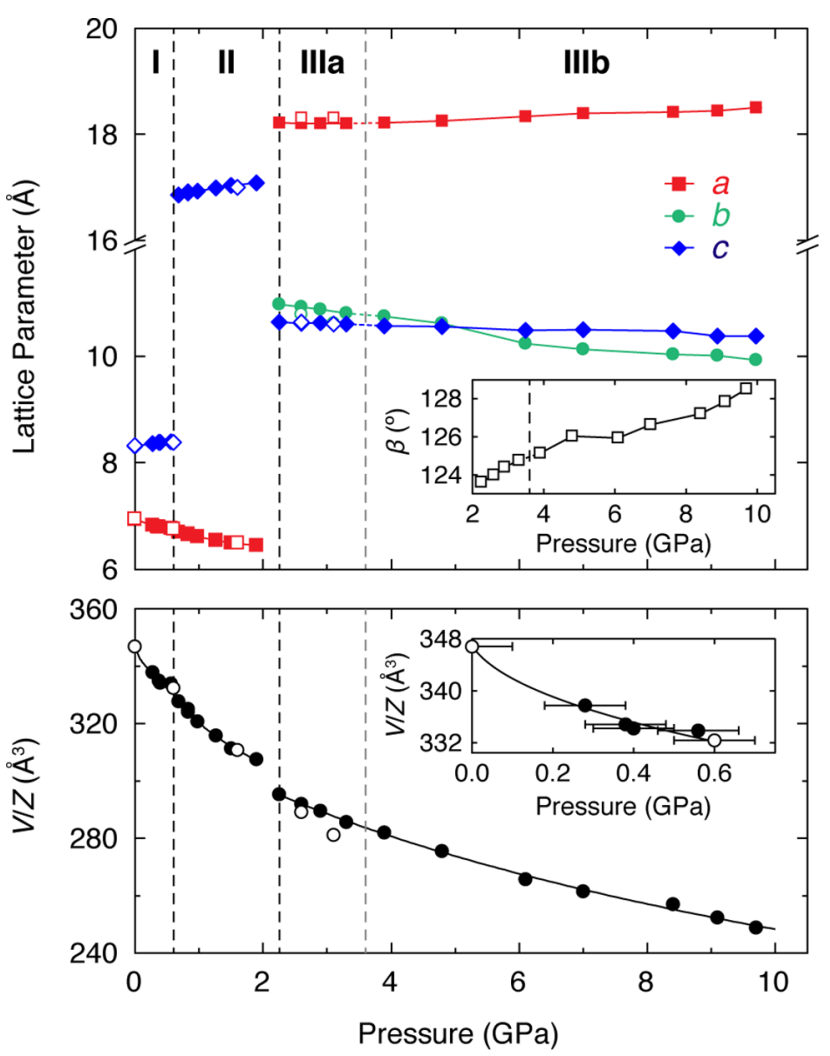

Figure 6. Evolution of structural parameters in $\mathrm{KCd}\left[\mathrm{Ag}(\mathrm{CN})_{2}\right]_{3}$ on application of hydrostatic pressure. (a) Lattice parameter changes observed during hydrostatic compression: $a$ (red squares), $b$ (green circles), and $c$ (blue diamonds) for phases I, II, and IIIa/IIIb; closed symbols (powder X-ray diffraction) and open symbols (single-crystal $\mathrm{X}$-ray diffraction). The approximate positions of phase transitions are indicated by dashed vertical lines. Error bars for both lattice parameters and pressure values are included within the area of the symbols. (inset) The variation in the monoclinic cell angle $\beta$ in phase III. (b) Normalized unit cell volumes (black squares) across the full pressure range studied fitted to lattice parameters extracted from powder diffraction by a modified third-order Birch-Murnaghan equation of state, as given in ref 60 . (inset) The B-M fit to the lowpressure data of phase I shows rapid structure stiffening approaching the phase I/II transition.

this value, and fitting across both phases gives an average bulk modulus of $11.9(5) \mathrm{GPa}$. All compressibilities and B-M coefficients calculated using $\mathrm{PASCal}^{59}$ are presented in Table 3.

ii. Structure and Compressibility of $\mathrm{KCd}\left[\mathrm{Ag}(\mathrm{CN})_{2}\right]_{3}-$ III. At $2.6 \mathrm{GPa}$, a single-crystal diffraction pattern was observed that was very different to the $P 312$ cell, which is consistent with the major phase transition observed by the Raman spectroscopic measurements. The unit cell could initially be indexed with a rhombohedral unit cell in space group $R 32$ for the two highest pressure points measured based on the observed reflection conditions. Closer inspection of these data indicated that the structure is actually monoclinic and belongs to the $C 2$ subgroup of $R 32$, which allows a shearing of the structure perpendicular to the $c$ axis. The transformation matrix to phase III (C2) with respect to the ambient pressure phase $\mathrm{KCd}\left[\mathrm{Ag}(\mathrm{CN})_{2}\right]_{3}-\mathrm{I}(P 312)$ is

$$
\mathbf{P}=\left[\begin{array}{lll}
1 & 1 & 1 \\
0 & 2 & 0 \\
-2 & 0 & 1
\end{array}\right]
$$

The transformation for the unit cell dimensions is therefore given as $a_{\text {III }}=a_{I}-2 c_{I}, b_{I I I}=a_{I}+2 b_{I}$, and $c_{I I I}=a_{I}+c_{I}$. As in the case of the intermediate phase, there is also a superstructure evident in the highest-pressure $C 2$ data, with weak superlattice reflections indicating a further doubling along all three directions. This results in a very large unit cell that cannot be refined from our data but which can resolve the formal relationship between phase II and the true phase III.

In order to solve this structure, a model based on the heavy atom positions only of the ambient pressure structure was initially refined against powder diffraction data. The implementation of ISODISTORT ${ }^{44}$ within TOPAS $^{46}$ was used to directly refine the symmetry modes with highest amplitude that cause the transition. By using the groupsubgroup relationship (P312 $\rightarrow C 2$ ), fewer free parameters than a conventional Rietveld refinement are used and so a model could be refined. This model was then used as the starting point for the single-crystal structure refinement; from this, the $\mathrm{C}$ and $\mathrm{N}$ atoms were readily located on the difference Fourier maps and their positions refined (Table 4). The presence of superlattice reflections suggests this solution is in itself still a spatially averaged structure and the true cell is doubled along all three directions. The complexity of the true structure prevents its full determination using data obtained at high pressure. Further refinement details, structural parameters, and atomic positions are given in full in the Supporting Information.

The structure refinements at 2.6 and $3.1 \mathrm{GPa}$ show that phase III is topologically identical to the ambient pressure phase. Major symmetry-breaking distortions are (i) buckling of the dicyanoargentate linkages, (ii) the offsetting of each network in the c direction, and (iii) the "rippling" of layers of argentophilic interactions (Figure 7). The major angle change occurs as a result of $\left[\mathrm{CdN}_{6}\right]$ rotations with a reduction in the $\mathrm{C}-\mathrm{N}-\mathrm{Cd}$ angle from $\sim 158.3^{\circ}$ in phases I and II to an average value of $150.3^{\circ}$ in phase III. The dicyanoargentate linker unit remains remarkably linear with a reduction in $\mathrm{C}-\mathrm{Ag}-\mathrm{C}$ of only $2^{\circ}$ up to $2.6 \mathrm{GPa}$; this rigidity is due to the energetically favorable $\mathrm{CN}$ back-bonding to $\mathrm{Ag}$ which requires good orbital overlap (close to $180^{\circ}$ ). In the complex high- $p$ structure, it is

Table 3. Linear Compressibilities Calculated Using PASCal ${ }^{59}$ from Variable-Pressure Lattice Parameters for Phases I, II, and III of $\mathrm{KCd}\left[\operatorname{Ag}(\mathrm{CN})_{2}\right]_{3}$

$\begin{array}{lcl}\text { phase } & p_{c}(\mathrm{GPa}) & K_{a}\left(\mathrm{TPa}^{-1}\right) \\ \text { I } & 0 & +48(8)^{a} \\ \text { II } & 0.6 & +30(2) \\ \text { I + II } & 0 & +37.6(19) \\ \text { III } & 2.25 & +12.0(8)\end{array}$

$\begin{array}{ll}K_{b}\left(\mathrm{TPa}^{-1}\right) & K_{c}\left(\mathrm{TPa}^{-1}\right) \\ & -21(2)^{a} \\ & -10.0(8) \\ & -13.9(11) \\ +11.3(13) & -2.7(4)\end{array}$

$B_{0}(\mathrm{GPa})$
$<5^{b}$
$13.6(10)$
$11.9(5)$
$31(4)$

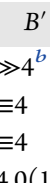

${ }^{a}$ Linear fit. ${ }^{b}$ Correlation between $B_{0}$ and $B^{\prime}$ gives large uncertainties on calculated values. 
Table 4. Single-Crystal X-ray Diffraction Data Collection and Refinement Details for $\mathrm{KCd}\left[\mathrm{Ag}(\mathrm{CN})_{2}\right]_{3}$-III at $p=2.6$ GPa and Room Temperature ${ }^{a}$

\begin{tabular}{|c|c|c|c|}
\hline \multicolumn{2}{|l|}{ radiation } & \multicolumn{2}{|c|}{ Mo $\mathrm{K} \alpha, \lambda=0.71073 \AA$} \\
\hline formula & & $\mathrm{KCdAg}_{3} \mathrm{C}_{6} \mathrm{~N}_{6}$ & \\
\hline$Z$ & & 6 & \\
\hline crystal size $(\mu \mathrm{m})$ & & $170 \times 80 \times 3$ & \\
\hline crystal system & & monoclinic & \\
\hline space group & & $\mathrm{C} 2$ & \\
\hline$a(\AA)$ & & $18.312(6)$ & \\
\hline$b(\AA)$ & & $10.7833(8)$ & \\
\hline$c(\AA)$ & & $10.636(3)$ & \\
\hline$\beta(\operatorname{deg})$ & & $124.33(4)$ & \\
\hline$V\left(\AA^{3}\right)$ & & $1734.4(8)$ & \\
\hline$R\left(F_{\mathrm{obs}}>4 \sigma\right)$ & & 0.0659 & \\
\hline$x$ & $y$ & $z$ & $U_{\text {eq }}\left(\times 10^{-2} \AA^{2}\right)$ \\
\hline 0 & $0.0429(9)$ & 0 & $3.8(5)$ \\
\hline $0.3000(2)$ & $0.0432(7)$ & $0.6997(2)$ & $3.6(3)$ \\
\hline 0 & $0.0388(9)$ & 0.5 & $3.6(6)$ \\
\hline $0.7477(4)$ & $-0.2043(8)$ & $-0.0038(6)$ & $4.8(4)$ \\
\hline $0.3148(3)$ & $0.0348(8)$ & $0.2145(4)$ & $4.3(5)$ \\
\hline $0.0453(4)$ & $-0.2177(7)$ & $0.6785(5)$ & $4.4(3)$ \\
\hline $0.0550(4)$ & $-0.6881(8)$ & $0.6908(5)$ & $4.4(3)$ \\
\hline 0 & 0.6667 & 0 & $2.5(10)$ \\
\hline $0.8126(7)$ & $-0.7692(8)$ & $0.6238(9)$ & $2.5(1.0)$ \\
\hline$-0.046(2)$ & $0.054(2)$ & $-0.256(3)$ & $2.6(7)^{b}$ \\
\hline $0.347(2)$ & $0.061(2)$ & $0.956(3)$ & $2.9(6)^{b}$ \\
\hline $0.271(2)$ & $-0.010(3)$ & $0.450(4)$ & $3.1(7)^{b}$ \\
\hline $0.186(2)$ & $0.181(2)$ & $0.643(3)$ & $2.6(6)^{b}$ \\
\hline $0.211(2)$ & $-0.112(2)$ & $0.672(4)$ & $4.2(8)^{b}$ \\
\hline $0.393(2)$ & $-0.318(2)$ & $-0.054(3)$ & $2.2(6)^{b}$ \\
\hline $0.431(2)$ & $-0.065(2)$ & $0.785(3)$ & $2.2(6)^{b}$ \\
\hline $0.373(2)$ & $0.202(2)$ & $0.675(3)$ & $3.0(6)^{b}$ \\
\hline $0.099(3)$ & $-0.116(2)$ & $0.035(4)$ & $3.7(9)^{b}$ \\
\hline $0.843(3)$ & $-0.138(3)$ & $-0.026(4)$ & $2.5(10)^{b}$ \\
\hline $0.847(3)$ & $-0.771(3)$ & $-0.029(4)$ & $2.0(8)^{b}$ \\
\hline $0.138(2)$ & $-0.762(2)$ & $0.655(3)$ & $1.3(7)^{b}$ \\
\hline $0.151(3)$ & $-0.155(3)$ & $0.665(4)$ & $2.9(9)^{b}$ \\
\hline$-0.026(3)$ & $-0.609(3)$ & $0.750(4)$ & $3.7(9)^{b}$ \\
\hline $0.338(2)$ & $0.057(3)$ & $0.053(4)$ & $3.3(8)^{b}$ \\
\hline$-0.023(2)$ & $0.049(5)$ & $-0.336(4)$ & $3.8(9)^{b}$ \\
\hline$-0.068(2)$ & $-0.266(2)$ & $0.674(3)$ & $1.7(6)^{b}$ \\
\hline $0.294(2)$ & $0.005(2)$ & $0.372(5)$ & $2.3(8)^{b}$ \\
\hline
\end{tabular}

${ }^{a}$ Estimated standard errors are given in parentheses. ${ }^{b}$ Refined isotropically.

found that all other bond distances decrease and variation in angles suggests a gradual buckling and densification of the structure (Figure $7 \mathrm{~d}$ ). Around each $\mathrm{K}^{+}$extra-framework cation, side-bound cyanides get progressively more close-packed in nature to create an irregular coordination of more than six cyanides (Figure $7 \mathrm{e}$ ).

Within the argentophilic layers - found to be key in driving the phase transition in the unstabilized $\mathrm{Ag}_{3}\left[\mathrm{Co}(\mathrm{CN})_{6}\right]$ (ref 18) - it is found that here $\mathrm{Ag}^{+}$displace up/down in the original c direction, shown schematically in Figure $7 \mathrm{~b}$. This rippling distortion maintains favorable argentophilic interactions but allows more extreme buckling of the cubic network and closer packing. In fact, these displacements occur for the entirety of each of the interpenetrated networks, also allowing the $\mathrm{Cd}^{2+}$ to move out of plane to reduce overall crystal volume. Critically, this distortion mechanism is distinct from that seen
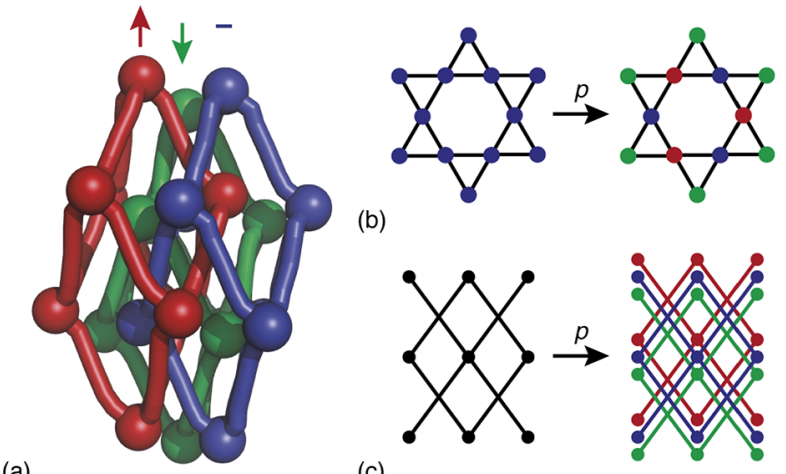

(b)

(a)

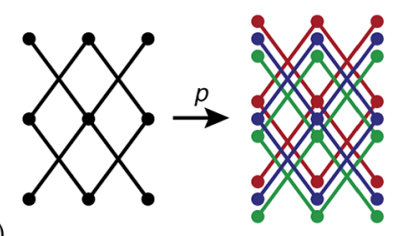

(c)
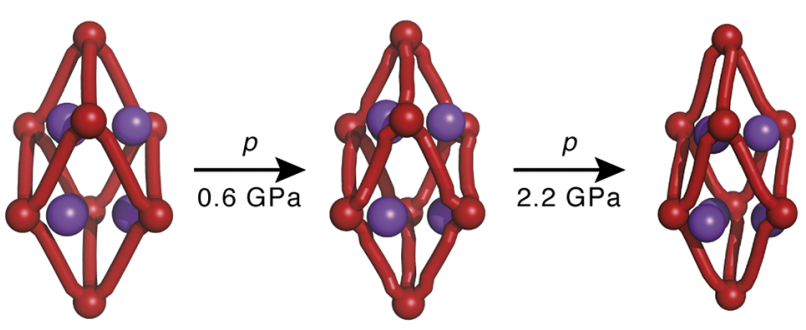

(d) P312

P312-2c

C2

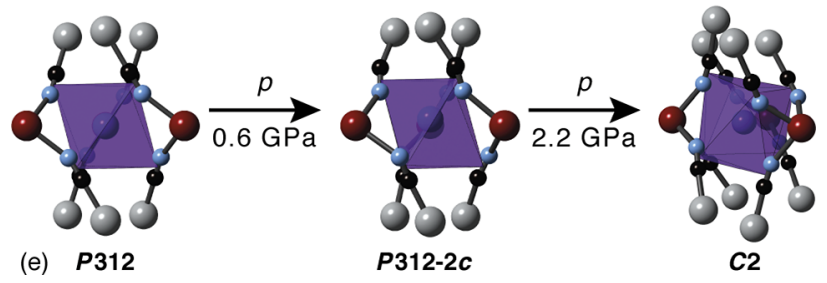

Figure 7. Structural features of high-pressure phase transitions in $\mathrm{KCd}\left[\mathrm{Ag}(\mathrm{CN})_{2}\right]_{3}$. (a) The main effect upon transition to phase III is the displacement of the distorted cubic nets in the $c$ direction: $1 / 3$ shift upward (red), 1/3 downward (green), and 1/3 remain as for phase II. This is accompanied by a shear of the structure. Such a transition results in the rippling of the argentophilic Kagome planes (b), but retention of the essential features of the "wine-rack" framework, and hence the retention of NLC, in the high-pressure structure (c). Each phase transition results in buckling of the structure $(\mathrm{d})$, but the $\left[\mathrm{Ag}(\mathrm{CN})_{2}\right]^{-}$linker remains remarkably linear. (e) The coordination around each $\mathrm{K}^{+}$becomes both more distorted and endon with neighboring cyanide units. Networks are shown schematically as for Figure 1 ; Cd, C, N, Ag, and $\mathrm{K}$ atoms are shown as red, black, blue, silver, and purple spheres, respectively.

in $\mathrm{Ag}_{3}\left[\mathrm{Co}(\mathrm{CN})_{6}\right]$; the soft modes responsible for the transition in the unstabilized dicyanometallate are frustrated, preventing the low-pressure reconstructive phase transition observed in that system. At much higher pressures, we observe clearly distinct phase transition behavior.

At $\sim 3.6 \mathrm{GPa}$, an additional set of Bragg reflections appear in our powder diffraction data. Due to the broadening of the data and the fact that this scattering was observed well above the hydrostatic limit of our experiment, no further attempt was made to solve this structure. Here we denote this as the transition IIIa $\rightarrow$ IIIb; there appears to be no hysteresis in either lattice parameter or volume data, so the transition is continuous. Using the refined lattice parameters for both IIIa/ IIIb, we can calculate average compressibilities along principal directions (Figure 8) and a bulk modulus for phase III. As is expected following a first-order phase transition, the compressibilities and bulk modulus evidence a significant stiffening of the structure. Reduction in the unit cell volumes of 


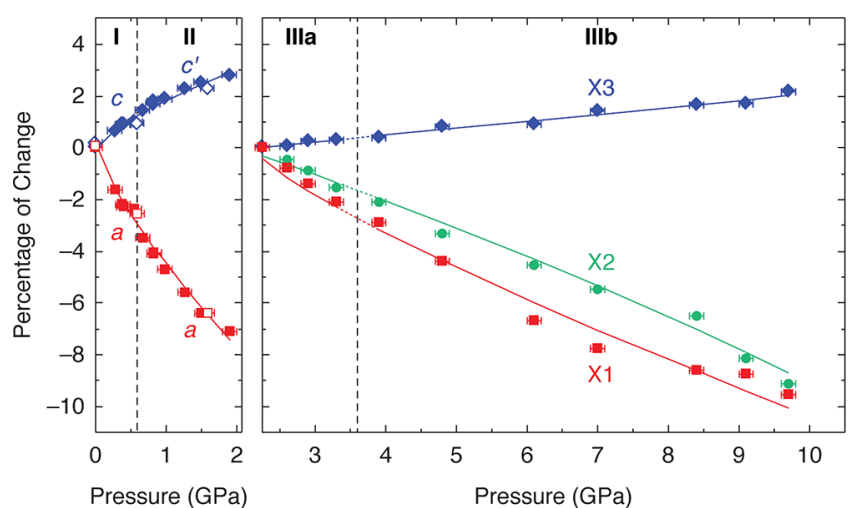

Figure 8. Fits to unit cell parameters along principal axes for phase I/ II (left panel) and IIIa and IIIb (right panel) using empirical equations as defined in ref 59 . In the trigonal space group of phases I and II, the principal axes are coincident with the $a$ (red squares) and $c$ (blue diamonds) lattice parameters. Phases I and II are fitted simultaneously as empirical fits to phase I only are not robust; however, linear fits to these data give equivalent compressibilities to the fit across both phases as described in the text. In the high-pressure phases IIIa and IIIb, the X2 (green circle) principal axis is coincident with $b$, while X1 and X2 lie approximately along $a$ and $c$, respectively. Vertical dashed lines indicate phase transition boundaries; closed symbols (powder X-ray diffraction) and open symbols (single-crystal X-ray diffraction).

phase III is well described by a second-order BM EoS $\left(B^{\prime} \equiv 4\right)$, suggesting the structure acts much more like conventional materials at these pressures. Remarkably, however, NLC is still observed along one principal direction that lies approximately along the $c$ axis of the $P 312$ cell; the retention of framework topology is such that-despite significant densificationmechanical hinging can still occur.

\section{DISCUSSION}

From a combination of diffraction and spectroscopic measurements, it is possible to reflect in much greater detail on the mechanism of NLC in this family of materials. While diffraction experiments may be used to determine the bulk mechanical response, packing effects, and bond distances, spectroscopic measurements are exceptionally sensitive to changes in bonding character. It is clear from our experiments that the phase transitions observed here are distinct from that of $\mathrm{Ag}_{3}\left[\mathrm{Co}(\mathrm{CN})_{6}\right]$, suggesting the presence of a counterion is key to the greater pressure range of response in these stabilized analogues.

We may consider the changes in bonding by discussing the distinct regions where certain interactions are dominant. The bonding between cyanide and $\mathrm{Ag}$ illustrates some of the successes and limitations of our spectroscopic data. In the high-wavenumber region where $\mathrm{CN}$ stretching is found, we observe an increase in wavenumber in both phases I and II and then a discontinuous decrease. From our diffraction refinements, we see on average a decrease in bond lengths and increasing distortion of the $\mathrm{Cd}-\mathrm{CN}-\mathrm{Ag}$ linker. Tentatively, we assigned the increase in vibrational wavenumber to decreasing bond lengths in phases I and II. The very discontinuous drop between phases II and III suggests a dramatic change in electronic structure. The extent of $\pi$-back bonding in $\mathrm{Ag}-\mathrm{CN}$ complexes from many computational studies $^{56}$ is controversial, although most agree there are important metal-ligand multiple bonding effects, while $\sigma$ - overlap is known to be significant. Thus, it appears that the large discontinuity is directly related to the return to more linear bonding in phase III than phase II, which we find evidence for in our crystallographic models, so $\pi$ overlap is improved maximizing backbonding, therefore weakening the $\mathrm{C} \equiv \mathrm{N}$ bond due to removal of electron density from the $1 \pi$ molecular orbitals. The trend in phases I and II can therefore be interpreted in terms of increasing deviation from linearity that leads to more electron density on $\mathrm{CN}$, therefore strengthening and shortening this bond. For phase II, both cyanides tilt in the same direction according to the $\left[\mathrm{CdN}_{6}\right]$ tilts found from our crystallographic models. The result is that the twisting $\mathrm{C}-\mathrm{Ag}-\mathrm{C}$ modes soften along with the stiffening of the stretching $\mathrm{CN}$ bonds, due to weaker $\mathrm{Ag}-\mathrm{CN}$ bonding. $\mathrm{A}$ further effect may be the side-on interaction from $\mathrm{K}^{+}$in the system at high pressure, that would have the effect of removing electron density from the $\mathrm{CN}$, thus weakening this bond.

Changes in the Ag kagomé breathing modes also reflect changes observed from diffraction, coupled with electronic factors. In phases I and II, there is no appreciable change in the Ag breathing modes, despite decreasing bond lengths measured from diffraction that would suggest increasing wavenumber. As the strength of bonding between $\mathrm{Ag}$ and $\mathrm{CN}$ increases and electronic density is removed from $\mathrm{Ag}$, we might expect an increase in electrostatic repulsion and hence a decrease in the strength of argentophilic interactions. In phase III, the distortion of the kagomé network to a rippled sheet clearly reduces the $\mathrm{Ag}-\mathrm{Ag}$ bonding interaction due to an increase in $\mathrm{Ag}-\mathrm{Ag}$ bond lengths and thus a significant decrease in argentophilicity.

For $\mathrm{Cd}-\mathrm{CN}$ stretching, scissoring, and twisting modes, a general stiffening of modes is observed. This can be correlated with the systematic and general decrease in $\mathrm{M}-\mathrm{CN}$ bonding, an increase in ionic character in the bonding $\left(\mathrm{Ag}(\mathrm{CN})_{2}\right.$ as a molecular unit), and more dense packing around the $\mathrm{K}^{+}$by side-on bonding of $\mathrm{CN}$. For example, with the onset of phase III, a hardening of the $\mathrm{CN}-\mathrm{K}-\mathrm{NC}$ twisting/wagging modes is observed, suggesting stronger bonding/interaction. In phase III, the splitting of many modes makes identification of individual effects difficult to interpret; however, it appears some modes soften due to the lowering of symmetry, thus differentiating some cyanides becoming more strongly bonded ionically to the cations, and others moving away.

\section{CONCLUSIONS}

$\mathrm{KCd}\left[\mathrm{Ag}(\mathrm{CN})_{2}\right]_{3}$ has the largest NLC response of this family of materials measured to date. Here we have explored the correspondence between thermo- and piezomechanical responses and the local and average structure mechanism of this unusual response. The studies presented here confirm the soft-mode frustration mechanism, proposed in our original report of $\mathrm{NLC}$ in $\mathrm{KMn}\left[\mathrm{Ag}(\mathrm{CN})_{2}\right]_{3}$ (ref 19), to describe the improvement in resistance to pressure-induced phase transition. Indeed, the phase transitions found in this family of stabilized frameworks are distinct from those observed in the guest-free analogue-upon application of pressure, a series of phase transitions occur that relate to the buckling of the framework via octahedral tilting, coordination geometry distortion, and concerted shifting of the three interpenetrated frameworks relative to each other to increase packing density. We observe the transition from the open, responsive framework structure of the ambient-pressure material to a phase that has bulk behavior much more like conventional 
materials at high pressure. Our spectroscopic studies, in combination with crystallographic data, allow enhanced interpretation of the bond angle and distance changes, and therefore electronic structure, that drives the high-pressure phase transitions. Finally, it is shown that NLC persists across all of the phase transitions.

\section{ASSOCIATED CONTENT}

\section{SI Supporting Information}

The Supporting Information is available free of charge at https://pubs.acs.org/doi/10.1021/acs.jpcc.9b11399.

Variable-pressure X-ray single-crystal diffraction refinement and structural information, variable-pressure X-ray powder diffraction data and fits, and variable-pressure lattice parameter values and crystallographic data in CIF format (CCDC 1983116-1983120) (PDF)

\section{AUTHOR INFORMATION}

\section{Corresponding Author}

Andrew B. Cairns - Department of Materials, Imperial College London, London SW7 2AZ, United Kingdom; Department of Chemistry, University of Oxford, Oxford OX1 3QR, United Kingdom; 이잉.org/0000-0003-4951-4937;

Email: a.cairns@imperial.ac.uk

\section{Authors}

Jadna Catafesta - Institut Charles Gerhardt Montpellier, UMR 5253 CNRS, Universite de Montpellier, Montpellier 34095 Cedex 5, France; Laboratoire Charles Coulomb, UMR 5221, CNRS, Université de Montpellier, Montpellier 34095, France

Patrick Hermet - Institut Charles Gerhardt Montpellier, UMR 5253 CNRS, Université de Montpellier, Montpellier 34095 Cedex 5, France; O orcid.org/0000-0001-8312-3740

Jérôme Rouquette - Institut Charles Gerhardt Montpellier, UMR 5253 CNRS, Universite de Montpellier, Montpellier 34095 Cedex 5, France

Claire Levelut - Laboratoire Charles Coulomb, UMR 5221, CNRS, Universite de Montpellier, Montpellier 34095, France

David Maurin - Laboratoire Charles Coulomb, UMR 5221, CNRS, Universite de Montpellier, Montpellier 34095, France

Arie van der Lee - Institut Européen des Membranes, UMRCNRS 5635, Universite de Montpellier, Montpellier 34095 Cedex 5, France

Vladimir Dmitriev - SNBL at ESRF, Grenoble 38043, France Jean-Louis Bantignies - Laboratoire Charles Coulomb, UMR 5221, CNRS, Université de Montpellier, Montpellier 34095, France

Andrew L. Goodwin - Department of Chemistry, University of Oxford, Oxford OX1 3QR, United Kingdom

Julien Haines - Institut Charles Gerhardt Montpellier, UMR 5253 CNRS, Universite de Montpellier, Montpellier 34095 Cedex 5, France; (1) orcid.org/0000-0002-7030-3213

Complete contact information is available at:

https://pubs.acs.org/10.1021/acs.jpcc.9b11399

\section{Notes}

The authors declare no competing financial interest.

\section{ACKNOWLEDGMENTS}

J.C., P.H., C.L., D.M., J.-L.B., and J.H. thank the Agence Nationale de la Recherche (project ANR-09-BLAN-0018-01) for financing this study. A.B.C. and A.L.G. gratefully acknowl- edge financial support from the ERC (Grant Nos. 279705 and 788144) and EPSRC (Grant No. EP/G004528/2). A.B.C. thanks Imperial College London for financial support. We thank the Swiss-Norwegian Beamline at the ESRF for allocation of beamtime (Proposal No. HS4434).

\section{REFERENCES}

(1) Barrera, G D; Bruno, J A O; Barron, T H K; Allan, N L Negative Thermal Expansion. J. Phys.: Condens. Matter 2005, 17, R217-R252.

(2) Evans, J. S. O. Negative Thermal Expansion Materials. J. Chem. Soc., Dalton Trans. 1999, 3317-3326.

(3) Coates, C. S.; Goodwin, A. L. How to quantify isotropic negative thermal expansion: magnitude, range, or both? Mater. Horiz. 2019, 6, 211-218.

(4) Baughman, R. H.; Stafstrom, S.; Cui, C. X.; Dantas, S. O. Materials with Negative Compressibilities in One or More Dimensions. Science 1998, 279, 1522-1524.

(5) Cairns, A. B.; Goodwin, A. L. Negative Linear Compressibility. Phys. Chem. Chem. Phys. 2015, 17, 20449-20465.

(6) Munn, R. W. Role of the Elastic Constants in Negative Thermal Expansion of Axial Solids. J. Phys. C: Solid State Phys. 1972, 5, 535.

(7) Ortiz, A. U.; Boutin, A.; Fuchs, A. H.; Coudert, F.-X. Anisotropic Elastic Properties of Flexible Metal-Organic Frameworks: How Soft are Soft Porous Crystals? Phys. Rev. Lett. 2012, 109, 195502.

(8) Ortiz, A. U.; Boutin, A.; Fuchs, A. H.; Coudert, F.-X. MetalOrganic Frameworks with Wine-Rack Motif: What Determines their Flexibility and Elastic Properties? J. Chem. Phys. 2013, 138, 174703.

(9) Baughman, R. H.; Cui, C.; Zakhidov, A.; Iqbal, Z.; Stafström, S.; Dantas, S. Optical Sensors Using Materials With Unusual Mechanical Properties or Photonic Bandgaps. Proceedings of the 10th Annual Meeting of the Lasers and Electro-Optics Society, San Francisco, CA, November 10-13, 1997; IEEE: Piscataway, NJ, 1997; pp 246-247.

(10) Baughman, R. H. Auxetic Materials: Avoiding the Shrink. Nature 2003, 425, 667-667.

(11) Miller, W.; Smith, C. W.; Mackenzie, D. S.; Evans, K. E. Negative Thermal Expansion: A Review. J. Mater. Sci. 2009, 44, $5441-5451$.

(12) Newnham, R. E. Properties of Materials: Anisotropy, Symmetry, Structure; Oxford University Press: Oxford, U.K., 2005.

(13) Stepanov, I. A. Thermodynamics of Substances with Negative Thermal Expansion and Negative Compressibility. J. Non-Cryst. Solids 2010, 356, 1168-1172.

(14) Takenaka, K. Negative Thermal Expansion Materials: Technological Key for Control of Thermal Expansion. Sci. Technol. Adv. Mater. 2012, 13, 013001.

(15) Hazen, R. M., Downs, R. T., Eds. High-Temperature and HighPressure Crystal Chemistry; Mineralogical Society of America: Blacksburg, VA, 2000; Vol. 41.

(16) Nye, J. F. Physical Properties of Crystals: Their Representation by Tensors and Matrices; Clarendon Press: Oxford, U.K., 1984.

(17) Goodwin, A. L.; Calleja, M.; Conterio, M. J.; Dove, M. T.; Evans, J. S. O.; Keen, D. A.; Peters, L.; Tucker, M. G. Colossal Positive and Negative Thermal Expansion in the Framework Material $\mathrm{Ag}_{3}\left[\mathrm{Co}(\mathrm{CN})_{6}\right]$. Science 2008, 319, 794-797.

(18) Goodwin, A. L.; Keen, D. A.; Tucker, M. G. Large Negative Linear Compressibility of $\mathrm{Ag}_{3} \mathrm{Co}(\mathrm{CN})_{6}$. Proc. Natl. Acad. Sci. U. S. A. 2008, 105, 18708-18713.

(19) Cairns, A. B.; Thompson, A. L.; Tucker, M. G.; Haines, J.; Goodwin, A. L. Rational Design of Materials with Extreme Negative Compressibility: Selective Soft-Mode Frustration in $\mathrm{KMn}\left[\mathrm{Ag}(\mathrm{CN})_{2}\right]_{3}$ . J. Am. Chem. Soc. 2012, 134, 4454-4456.

(20) Korčok, J. L.; Katz, M. J.; Leznoff, D. B. Impact of Metallophilicity on "Colossal" Positive and Negative Thermal Expansion in a Series of Isostructural Dicyanometallate Coordination Polymers. J. Am. Chem. Soc. 2009, 131, 4866-4871.

(21) Goodwin, A. L.; Kennedy, B. J.; Kepert, C. J. Thermal Expansion Matching via Framework Flexibility in Zinc Dicyanometallates. J. Am. Chem. Soc. 2009, 131, 6334-6335. 
(22) Cairns, A. B.; Catafesta, J.; Levelut, C.; Rouquette, J.; van der Lee, A.; Peters, L.; Thompson, A. L.; Dmitriev, V.; Haines, J.; Goodwin, A. L. Giant Negative Linear Compressibility in Zinc Dicyanoaurate. Nat. Mater. 2013, 12, 212-216.

(23) Coudert, F.-X. Metal-organic frameworks: the pressure is on. Acta Crystallogr., Sect. B: Struct. Sci., Cryst. Eng. Mater. 2015, 71, 585586.

(24) Serra-Crespo, P.; Dikhtiarenko, A.; Stavitski, E.; Juan-Alcaniz, J.; Kapteijn, F.; Coudert, F.-X.; Gascon, J. Experimental Evidence of Negative Linear Compressibility in the MIL-53 Metal-Organic Framework Family. CrystEngComm 2015, 17, 276-280.

(25) Binns, J.; Kamenev, K. V.; Marriott, K. E. R.; McIntyre, G. J.; Moggach, S. A.; Murrie, M.; Parsons, S. A non-topological mechanism for negative linear compressibility. Chem. Commun. 2016, 52, 74867489.

(26) Gagnon, K. J.; Beavers, C. M.; Clearfield, A. MOFs Under Pressure: The Reversible Compression of a Single Crystal. J. Am. Chem. Soc. 2013, 135, 1252-1255.

(27) Li, W.; Probert, M. R.; Kosa, M.; Bennett, T. D.; Thirumurugan, A.; Burwood, R. P.; Parinello, M.; Howard, J. A. K.; Cheetham, A. K. Negative Linear Compressibility of a Metal-Organic Framework. J. Am. Chem. Soc. 2012, 134, 11940-11943.

(28) Collings, I. E.; Tucker, M. G.; Keen, D. A.; Goodwin, A. L. Geometric Switching of Linear to Area Negative Thermal Expansion in Uniaxial Metal-Organic Frameworks. CrystEngComm 2014, 16, 3498-3506.

(29) Cai, W.; Katrusiak, A. Giant Negative Linear Compression Positively coupled to Massive Thermal Expansion in a Metal-Organic Framework. Nat. Commun. 2014, 5, 4337.

(30) Chibani, S.; Coudert, F.-X. Systematic Exploration of the Mechanical Properties of 13,621 Inorganic Compounds. Chem. Sci. 2019, 10, 8589-8599.

(31) Dong, W.; Zhu, L.; Sun, Y.; Liang, M.; Liu, Z.; Liao, D.; Jiang, Z.; Yan, S.; Cheng, P. 3D porous and 3D interpenetrating triple framework structures constructed by aurophilicity - coordination interplay in $\left\{\left[\mathrm{Mn}\left[\mathrm{Au}(\mathrm{CN})_{2}\right]_{2} \cdot 2 \mathrm{H}_{2} \mathrm{O}\right\}_{n}\right.$ and $\left\{\mathrm{KFe}\left[\mathrm{Au}(\mathrm{CN})_{2}\right]{ }_{3}\right\}_{n}$. Chem. Commun. 2003, 20, 2544-2545.

(32) Hill, J. A.; Thompson, A. L.; Goodwin, A. L. Dicyanometallates as Model Extended Frameworks. J. Am. Chem. Soc. 2016, 138, 58865896.

(33) Hill, J. A.; Cairns, A. B.; Lim, J. J. K.; Cassidy, S. J.; Clarke, S. J.; Goodwin, A. Zero-Strain Reductive Intercalation in a Molecular Framework. CrystEngComm 2015, 17, 2925-2928.

(34) Collings, I. E.; Cairns, A. B.; Thompson, A. L.; Parker, J. E.; Tang, C. C.; Tucker, M. G.; Catafesta, J.; Levelut, C.; Haines, J.; Dmitriev, V.; et al. Homologous critical behavior in the molecular frameworks $\mathrm{Zn}(\mathrm{CN})_{2}$ and $\mathrm{Cd}(\text { imidazolate })_{2}$. J. Am. Chem. Soc. 2013, 135, 7610-7620.

(35) Goodwin, A. L.; Chapman, K. W.; Kepert, C. J. GuestDependent Negative Thermal Expansion in Nanoporous Prussian Blue analogues $\mathrm{M}^{\mathrm{II}} \mathrm{Pt}^{\mathrm{IV}}(\mathrm{CN})_{6} \cdot x\left\{\mathrm{H}_{2} \mathrm{O}\right\}(0 \leq x \leq 2 ; \mathrm{M}=\mathrm{Zn}, \mathrm{Cd}) . J$. Am. Chem. Soc. 2005, 127, 17980-17981.

(36) Goodwin, A. L.; Keen, D. A.; Tucker, M. G.; Dove, M. T.; Peters, L.; Evans, J. S. O. Argentophilicity-Dependent Colossal Thermal Expansion in Extended Prussian Blue Analogues. J. Am. Chem. Soc. 2008, 130, 9660-9661.

(37) Kamali, K.; Ravi, C.; Ravindran, T. R.; Sarguna, R. M.; Sairam, T. N.; Kaur, G. Linear Compressibility and Thermal Expansion of $\mathrm{KMn}\left[\mathrm{Ag}(\mathrm{CN})_{2}\right]_{3}$ Studied by Raman Spectroscopy and FirstPrinciples Calculations. J. Phys. Chem. C 2013, 117, 25704-25713.

(38) Geiser, U.; Schlueter, J. A. $\mathrm{KMnAg}_{3}(\mathrm{CN})_{6}$, A New Triply Interpenetrating Network Solid. Acta Crystallogr., Sect. C: Cryst. Struct. Commun. 2003, C59, I21-I23.

(39) Klotz, S.; Chervin, J.-C.; Munsch, P.; Le Marchand, G. Hydrostatic Limits of 11 Pressure Transmitting Media. J. Phys. D: Appl. Phys. 2009, 42, 075413.

(40) Lapidus, S. H.; Halder, G. J.; Chupas, P. J.; Chapman, K. W. Exploiting High Pressures to Generate Porosity, Polymorphism, And
Lattice Expansion in the Nonporous Molecular Framework $\mathrm{Zn}(\mathrm{CN})_{2}$. J. Am. Chem. Soc. 2013, 135, 7621-7628.

(41) Murata, K.; Yokogawa, K.; Yoshino, H.; Klotz, S.; Munsch, P.; Irizawa, A.; Nishiyama, M.; Iizuka, K.; Nanba, T.; Okada, T.; et al. Pressure transmitting medium Daphne 7474 solidifying at $3.7 \mathrm{GPa}$ at room temperature. Rev. Sci. Instrum. 2008, 79, 085101.

(42) Angel, R.; Gonzalez-Platas, J. ABSORB-7 and ABSORB-GUI for single-crystal absorption corrections. J. Appl. Crystallogr. 2013, 46, 252-254.

(43) Sheldrick, G. M.; Schneider, T. R. SHELXL: High-resolution refinement. Methods Enzymol. 1997, 277, 319-343.

(44) Campbell, B. J.; Stokes, H. T.; Tanner, D. E.; Hatch, D. M. ISODISPLACE: A Web-Based Tool for Exploring Structural Distortions. J. Appl. Crystallogr. 2006, 39, 607-614.

(45) Hammersley, A. P. FIT2D: An Introduction and Overview; European Synchrotron Radiation Facility: Grenoble, France, 1997.

(46) Coelho, A. A. TOPAS-Academic, version 4.1; Coelho Software: Brisbane, Australia.

(47) Young, R. A., Ed. The Rietveld Method; IUCr Book Series; Oxford University Press: Oxford, U.K., 1993.

(48) Gonze, X.; Amadon, B.; Anglade, P. M.; Beuken, J. M.; Bottin, F.; Boulanger, P.; Bruneval, F.; Caliste, D.; Caracas, R.; Côtè, M.; et al. ABINIT: First-Principles Approach to Material and Nanosystem Properties. Comput. Phys. Commun. 2009, 180, 2582-2615.

(49) Perdew, J. P.; Wang, Y. Accurate and Simple Analytic Representation of the Electron-Gas Correlation Energy. Phys. Rev. B: Condens. Matter Mater. Phys. 1992, 45, 13244-13249.

(50) Troullier, N.; Martins, J. L. Efficient Pseudopotentials for Plane-Wave Calculations. Phys. Rev. B: Condens. Matter Mater. Phys. 1991, 43, 1993-2006.

(51) Monkhorst, H. J.; Pack, J. D. Special Points for Brillouin-Zone Integrations. Phys. Rev. B 1976, 13, 5188-5192.

(52) Gonze, X.; Lee, C. Dynamical Matrices, Born Effective Charges, Dielectric Permittivity Tensors, and Interatomic Force Constants from Density-Functional Perturbation Theory. Phys. Rev. B: Condens. Matter Mater. Phys. 1997, 55, 10355-10368.

(53) Hermet, P.; Bantignies, J.-L.; Rahmani, A.; Sauvajol, J.-L.; Johnson, M. R.; Serein, F. Far- and Mid-Infrared of Crystalline 2,2'Bithiophene: $\mathrm{Ab}$ Initio Analysis and Comparison with Infrared Response. J. Phys. Chem. A 2005, 109, 1684-1691.

(54) Hermet, P.; Veithen, M.; Ghosez, P. First-Principles Calculations of the Nonlinear Optical Susceptibilities and Raman Scattering Spectra of Lithium Niobate. J. Phys.: Condens. Matter 2007, 19,456202

(55) Griffith, W. P. Cyanide complexes of the transition metals. Q. Rev., Chem. Soc. 1962, 16, 188-207.

(56) Dietz, O.; Rayón, V. M.; Frenking, G. Molecular Structures, Bond Energies, and Bonding Analysis of Group 11 Cyanides $\mathrm{TM}(\mathrm{CN})$ and Isocyanides $\mathrm{TM}(\mathrm{NC})(\mathrm{TM}=\mathrm{Cu}, \mathrm{Ag}, \mathrm{Au})$. Inorg. Chem. 2003, 42, 4977-4984.

(57) Boström, H. L. B.; Hill, J. A.; Goodwin, A. L. Columnar shifts as symmetry-breaking degrees of freedom in molecular perovskites. Phys. Chem. Chem. Phys. 2016, 18, 31881-31894.

(58) Boström, H. L. B.; Senn, M. S.; Goodwin, A. L. Recipes for improper ferroelectricity in molecular perovskites. Nat. Commun. 2018, 9, 2380.

(59) Cliffe, M. J.; Goodwin, A. L. PASCal: A Principal Axis Strain Calculator for Thermal Expansion and Compressibility Determination. J. Appl. Crystallogr. 2012, 45, 1321-1329.

(60) Sata, N.; Shen, G.; Rivers, M. L.; Sutton, S. R. Pressure-Volume Equation of State of the High-Pressure B2 Phase of NaCl. Phys. Rev. B: Condens. Matter Mater. Phys. 2002, 65, 104114. 